\title{
Recombinant Anti-CD20 Antibody Fragments for Small-Animal PET Imaging of B-Cell Lymphomas
}

Tove Olafsen ${ }^{1}$, David Betting ${ }^{2}$, Vania E. Kenanova ${ }^{1}$, Felix B. Salazar ${ }^{1}$, Pat Clarke ${ }^{3}$, Jonathan Said ${ }^{4}$, Andrew A. Raubitschek ${ }^{3}$, John M. Timmerman ${ }^{2}$, and Anna M. Wu ${ }^{1}$

${ }^{I}$ Crump Institute for Molecular Imaging, Department of Molecular and Medical Pharmacology, David Geffen School of Medicine, University of California at Los Angeles, Los Angeles, California; ${ }^{2}$ Division of Hematology and Oncology, Department of Medicine, David Geffen School of Medicine, University of California at Los Angeles, Los Angeles, California; ${ }^{3}$ Department of Radioimmunotherapy, City of Hope National Medical Center, Duarte, California; and ${ }^{4}$ Department of Pathology and Laboratory Medicine, David Geffen School of Medicine, University of California at Los Angeles, Los Angeles, California

The CD20 cell surface antigen is expressed at high levels by over $90 \%$ of $\mathrm{B}$-cell non-Hodgkin lymphomas (NHL) and is the target of the anti-CD20 monoclonal antibody rituximab. To provide more sensitive, tumor-specific PET imaging of $\mathrm{NHL}$, we sought to develop PET agents targeting CD20. Methods: Two recombinant anti-CD20 rituximab fragments, a minibody (scFv- $\mathrm{C}_{\mathrm{H}} 3$ dimer; $80 \mathrm{kDa}$ ) and a modified scFv-Fc fragment (105 kDa), designed to clear rapidly, were generated. Both fragments were radiolabeled with ${ }^{124} \mathrm{I}$, and the minibody was additionally labeled with ${ }^{64} \mathrm{Cu}$ (radiometal) after conjugation to 1,4,7,10-tetraazacyclododecane- $N, N^{\prime}, N^{\prime \prime}, N^{\prime \prime \prime}$-tetraacetic acid (DOTA). The radioiodinated fragments and the radiometal-labeled minibody were evaluated in mice as small-animal PET imaging agents for the in vivo imaging of human CD20-expressing lymphomas. Results: Rapid and specific localization to CD20-positive tumors was observed with the radioiodinated fragments. However, the tumor uptake levels and blood activities differed, resulting in different levels of contrast in the images. The better candidate was the minibody, with superior uptake (2-fold higher than that obtained with scFv-Fc) in CD20-positive tumors and low uptake in CD20-negative tumors. Ratios of CD20-positive tumors to CD20-negative tumors at $21 \mathrm{~h}$ were $7.0 \pm 3.1$ (mean $\pm \mathrm{SD}$ ) and $3.9 \pm 0.7$ for the minibody and scFv-Fc, respectively. The ratio achieved with the ${ }^{64} \mathrm{Cu}$-DOTA-minibody at $19 \mathrm{~h}$ was about 5 -fold lower because of higher residual background activity in CD20-negative tumors. Conclusion: A radioiodinated minibody and a radioiodinated $\mathrm{scFv}-\mathrm{Fc}$ fragment produced excellent, high-contrast images in vivo. These new immunoPET agents may prove useful for imaging CD20-positive lymphomas in preclinical models and in humans with $\mathrm{NHL}$.

Key Words: Iymphoma; CD20; antibody fragments; immunoPET; rituximab

J Nucl Med 2009; 50:1500-1508

DOI: 10.2967/jnumed.108.060426

Received Nov. 20, 2008; revision accepted May 28, 2009. For correspondence or reprints contact: Tove Olafsen, UCLA Crump Institute for Molecular Imaging, California NanoSystems Institute, 570 Westwood Plaza, Building 114, Box 951770, Los Angeles, CA 90095-1770.

E-mail: tolafsen@mednet.ucla.edu

Guest Editor: Kenneth T. Cheng, National Institutes of Health

COPYRIGHT @ 2009 by the Society of Nuclear Medicine, Inc.
$\mathbf{N}$ on-Hodgkin lymphoma (NHL) is the fifth most common malignancy in the United States, accounting for approximately $4 \%$ of all cancers. Over $90 \%$ of NHL tumors are derived from $\mathrm{B}$ cells and express the B-cell differentiation antigen CD20. CD20 is an integral transmembrane protein expressed exclusively by cells in the B lineage, from normal pre-B-cell precursors through mature B cells, but not by terminally differentiated plasma cells (1). Although the precise functions of CD20 remain unknown, it is thought that CD20 plays a role in B-cell activation events, the regulation of cell growth, and transmembrane calcium flux (2). This 33 - to $37-\mathrm{kDa}$ nonglycosylated, hydrophobic, phosphorylated protein is not shed and undergoes very slow modulation or internalization in response to antibody binding, making it an ideal target for exogenous antibody therapies (2).

The chimeric (mouse-human) anti-CD20 antibody rituximab C2B8 (Rituxan; Genentech/Biogen-IDEC) has become a mainstay in the treatment of B-cell NHL, achieving high response rates for low-grade B-cell lymphomas (3) and improvements in survival for both low-grade and aggressive lymphomas when combined with chemotherapy $(4,5)$. The mechanism of action of rituximab in vivo appears to be mediated by antibody-dependent cell-mediated cytotoxicity, complement-mediated cell lysis, and the induction of apoptosis in tumor cells (6). The efficacy of anti-CD20 antibodies against lymphoma has been further enhanced through combinations with therapeutic radionuclides, such as ${ }^{131} \mathrm{I}$ (tositumomab [Bexxar]; Smithkline Beecham) and ${ }^{90} \mathrm{Y}$ (ibritumomab [Zevalin]; IDEC Pharmaceuticals Corp.) $(7,8)$.

The tracer ${ }^{18} \mathrm{~F}$-FDG is currently standard in clinical PET for many malignancies, but its utility for lymphomas can be limited in cases of indolent disease with low metabolic activity. The rate of tumor detection by ${ }^{18} \mathrm{~F}-\mathrm{FDG}$ PET in low-grade small lymphocytic and marginal-zone lymphomas can be as low as $50 \%(9,10)$. An imaging agent directed 
against a cell surface target could provide more sensitive, tumor-specific imaging. Recently, there has been a renewed interest in using antibodies for imaging malignancies (immunoPET). Antibodies radiolabeled with ${ }^{124} \mathrm{I},{ }^{64} \mathrm{Cu}$, and ${ }^{89} \mathrm{Zr}$ have been evaluated in patients with tumors (11). However, despite promising results, these PET tracers were all based on intact antibodies, and as a result, days were required for the activity levels to drop sufficiently to allow acceptable target-to-background ratios.

Redesigning antibodies without compromising their specificity by reducing their size results in rapid clearance from the blood, a desirable property for an imaging agent. We previously generated engineered antibody fragments, including diabodies (dimers of single-chain $\mathrm{Fv}$ [scFv]; $55 \mathrm{kDa}$ ) (12), minibodies (dimers of $\mathrm{scFv}_{-} \mathrm{C}_{\mathrm{H}} 3 ; 80 \mathrm{kDa}$ ) (13), and scFv-Fc fragments (dimers of scFv-Fc; $105 \mathrm{kDa}$ ), with pharmacokinetics optimized for imaging in vivo (14). Small-animal PET imaging with ${ }^{124} \mathrm{I}$ - or ${ }^{64} \mathrm{Cu}$-labeled fragments has demonstrated rapid, high-level tumor targeting to tumor-specific surface molecules, such as carcinoembryonic antigen (CEA) (colon carcinoma), HER2 (breast cancer), and prostate-stem cell antigen (PSCA) (prostate cancer), in tumor-bearing mice (14-18). The major advantage of using nonresidualizing labels (i.e., ${ }^{124}$ I) over residualizing labels (i.e., ${ }^{64} \mathrm{Cu}$ ) is the low background activity obtained in normal organs (e.g., liver and kidneys) with radioiodinated proteins. This difference is a result of differences in metabolism and clearance of activity after administration: metabolites (e.g., iodide or iodotyrosines) of radioiodinated proteins are quickly released from the cells and excreted via the kidneys, whereas metabolites of radiometal-chelated proteins are trapped in the cells, leading to increased retention of activity over time. When the anti-CEA T84.66 minibody was labeled with both labels and evaluated by small-animal PET imaging in tumor-bearing mice, the tumor-to-background ratios were 11 with the ${ }^{124}$ I-labeled minibody at $18 \mathrm{~h}$ and almost 2-fold lower (6.1) with the ${ }^{64} \mathrm{Cu}$-labeled minibody at $24 \mathrm{~h}(16,17)$.

Here we describe the generation of 2 anti-CD20 rituximab fragments, a minibody and a scFv-Fc fragment with mutations in 2 residues (H310A and H435Q) in the $\mathrm{Fc}$ region that have been shown to interfere with binding to the rodent neonatal $\mathrm{Fc}$ receptor (FcRn) (19). The fragments were radiolabeled with ${ }^{124} \mathrm{I}$ and evaluated as small-animal PET imaging agents for the in vivo imaging of human CD20-expressing lymphomas. Rapid and specific localization to CD20-positive tumors was observed. The tumor uptake levels and blood activities in the 2 fragments differed, resulting in different levels of contrast in the images. The best candidate was the minibody because of its superior uptake in CD20-positive tumors and rapid blood clearance, producing high-contrast images. The minibody was also radiolabeled with ${ }^{64} \mathrm{Cu}$ and evaluated in the same tumor model as the radioiodinated fragments. However, the minibody labeled with the stable or residualizing radiometal produced a high background signal in CD20-negative tumors and organs, resulting in relatively poor image contrast. These immunoPET agents may prove useful for imaging CD20-positive lymphomas in preclinical models and in humans with NHL.

\section{MATERIALS AND METHODS}

\section{Design and Gene Assembly of Anti-CD20 Antibody Fragments}

A polymerase chain reaction (PCR) with splice overlap extension (SOE-PCR) was used to create fully synthetic anti-CD20 variable $(\mathrm{V})$ genes based on the $\mathrm{V}$ gene sequences of murine 2B8 (20) as described previously (21). Full-length $2 \mathrm{~B} 8 \mathrm{~V}_{\mathrm{L}}$ and $\mathrm{V}_{\mathrm{H}}$ genes were then assembled by SOE-PCR to produce scFv with an 18residue linker (Whitlow 218 linker; GSTSGSGKPGSGEGSTKG) (22) in the $\mathrm{V}_{\mathrm{L}}-\mathrm{V}_{\mathrm{H}}$ orientation. After SOE-PCR, which also included a signal peptide at the $5^{\prime}$-end (upstream) to enable secretion, the construct was cloned into the pCR-2.1-TOPO vector (Invitrogen Corp.) and confirmed by sequencing.

The human IgG4 Fc including the hinge $\left(\mathrm{h}-\mathrm{C}_{\mathrm{H}} 2-\mathrm{C}_{\mathrm{H}} 3\right)$ was amplified by PCR and fused to $2 \mathrm{~B} 8 \mathrm{scFv}$ by another SOE-PCR to make chimeric scFv-Fc. With a Quick-Change Site-Directed $\mathrm{Mu}$ tagenesis Kit (Stratagene), specific mutations in the $\mathrm{C}_{\mathrm{H}} 2$ and $\mathrm{C}_{\mathrm{H}} 3$ domains (H310A and H435Q; EU index numbering) were introduced to eliminate binding to FcRn, creating the so-called doublemutant construct ( $\mathrm{scFv}-\mathrm{Fc} \mathrm{DM}$ ), as described previously (23). The minibody was assembled by initial amplification of the human IgG4 hinge and the $\mathrm{C}_{\mathrm{H}} 3$ domain, which were joined by SOE-PCR and fused to $2 \mathrm{~B} 8 \mathrm{scFv}$ by another SOE-PCR to produce a fulllength minibody construct. For correction of the deficiency of IgG4 in forming inter-heavy-chain bonds (24), a single mutation (S228P) was introduced into the core hinge region (CPSC; residues 226-229) of scFv-Fc DM and the minibody.

Finally, the minibody and scFv-Fc DM fragments were both inserted into the mammalian expression vector pEE12 at the $X b a \mathrm{I}$ and EcoRI sites as described previously (14). This vector contains the human cytomegalovirus promoter and the glutamine synthetase gene for selection.

\section{Expression, Selection, and Purification}

A total of $2 \times 10^{6} \mathrm{NS} 0$ mouse myeloma cells were transfected with $10 \mu \mathrm{g}$ of linearized (cut with SalI) vector DNA by electroporation and selected in glutamine-deficient medium (JHR Biosciences) as described previously (23). After 2-3 wk, supernatants were screened for expression by an enzyme-linked immunosorbent assay and analyzed for size by Western blotting as described previously (23). The minibody and scFv-Fc DM were captured by goat antihuman Fc-specific antibodies and detected by alkaline phosphatase-conjugated goat antihuman Fc-specific antibodies (both from Jackson ImmunoResearch Laboratories). The highestexpressing clones were expanded and brought to terminal cultures. Supernatants were passed over a protein L-agarose column (Thermo Fisher Scientific Inc.), and bound proteins were eluted with 5, 10, and 5 column volumes of $30 \%, 50 \%$, and $70 \% 0.2 \mathrm{M}$ citrate buffer ( $\mathrm{pH}$ 2.1) in phosphate-buffered saline (PBS), respectively, into $80 \%(\mathrm{v} / \mathrm{v}) 1 \mathrm{M}$ Tris base $(\mathrm{pH} 8.2)$. The eluted fractions containing the desired protein were dialyzed against PBS with Slide-A-Lyzer Dialysis Cassettes (Thermo Fisher Scientific Inc.) and then concentrated to $0.5-1.0 \mathrm{~mL}$ with Vivaspin 20 (Vivascience AG). The final concentration of purified protein was determined by 
measuring the absorbance at $280 \mathrm{~nm}$ with the extinction coefficient $1.4 \mathrm{mg} / \mathrm{mL}$.

\section{Biochemical Characterization of Purified Anti-CD20 Antibody Fragments}

Samples of purified proteins were analyzed by sodium dodecyl sulfate-polyacrylamide gel electrophoresis (SDS-PAGE) under nonreducing or reducing (1 mM dithiothreitol) conditions. Samples were also subjected to size exclusion high-pressure liquid chromatography with a Superdex-200 HR 10/30 column (GE Healthcare Bio-Sciences Corp.), a flow rate of $0.5 \mathrm{~mL} / \mathrm{min}$, and 50 $\mathrm{mM} \mathrm{Na}_{3} \mathrm{PO}_{4}-0.15 \mathrm{M} \mathrm{NaCl}$ ( $\mathrm{pH} 7.0$ ) buffer. Retention times were compared with standards of intact anti-CEA cT84.66 antibody, minibody, and diabody as described previously (14).

The binding of fragments to human CD20 was assessed by indirect immunofluorescence with the murine B-cell lymphoma line 38C13-huCD20 (described later). Cells $\left(5 \times 10^{5}\right)$ were incubated for $1 \mathrm{~h}$ on ice with $500 \mu \mathrm{L}$ of minibody or scFv-Fc at $5 \mu \mathrm{g} / \mathrm{mL}$ in PBS plus $1 \%$ fetal bovine serum. Cells were washed and stained with phycoerythrin (PE)-conjugated goat antihuman (Fc-specific) antibodies (Jackson ImmunoResearch Laboratories) at a 1:100 dilution for detection. Rituximab was used as a positive control.

\section{Radioiodination with ${ }^{124}$ |}

Purified rituximab minibody and $\mathrm{scFv}-\mathrm{Fc}$ DM (0.2 mg each) were radioiodinated with $17.1 \mathrm{MBq}(0.461 \mathrm{mCi})$ and $15.6 \mathrm{MBq}$ $(0.422 \mathrm{mCi})$, respectively, of the positron-emitting isotope ${ }^{124} \mathrm{I}$ (sodium iodide in $0.02 \mathrm{M} \mathrm{NaOH}$; radionuclide purity, >99\%) (IBA Molecular) by the IODO-GEN (Thermo Scientific) method as described previously $(14,23)$. Instant thin-layer chromatography with a Monoclonal Antibody ITLC Strips Kit (Biodex Medical Systems) was used to determine labeling efficiency as described previously (23). Immunoreactivity was assayed by incubating radioiodinated protein with an excess amount of 38C13-huCD20 cells for $1 \mathrm{~h}$, centrifuging the cells, and counting the activity remaining in the supernatant. Labeling efficiencies for scFv-Fc DM and the minibody, respectively, were $84.9 \%$ and $80.9 \%$, and immunoreactivities were $32.8 \%$ and $37.7 \%$.

\section{Minibody Conjugation and Radiolabeling with ${ }^{64} \mathrm{Cu}$}

Purified minibody was conjugated to 1,4,7,10-tetraazacyclododecane- $N, N^{\prime}, N^{\prime \prime}, N^{\prime \prime \prime}$-tetraacetic acid (DOTA; Macrocyclics) by the water-soluble $N$-hydroxysuccinimide method as described previously (25). The extent of modification was evaluated by isoelectric focusing (26).

The positron-emitting isotope ${ }^{64} \mathrm{Cu}$ (copper chloride in $0.1 \mathrm{M}$ $\mathrm{HCl}$; radionuclide purity, $>99 \%$ ) was provided by the Mallinckrodt Institute of Radiology (Washington University School of Medicine). The DOTA-conjugated anti-CD20 minibody $(200 \mu \mathrm{g})$ was incubated with $13.0 \mathrm{MBq}(0.35 \mathrm{mCi})$ of ${ }^{64} \mathrm{Cu}$ in $0.1 \mathrm{M} \mathrm{NH}_{4}$ citrate (pH 5.5) for $50 \mathrm{~min}$ at $43^{\circ} \mathrm{C}$. The labeling efficiency was $65.4 \%$, as determined with the Monoclonal Antibody ITLC Strips Kit.

\section{Syngeneic Human CD20-Expressing Murine Lymphoma Model}

The murine B-cell lymphoma line 38C13 (27) was stably transduced with the human CD20 gene by use of lentiviral vector pRRLsin.hEF1 $\alpha$.CD20.Wpre, which was provided by Josie Golay (28). Human CD20-positive cells were selected with anti-CD20 MACS Beads (Miltenyi Biotec), and then flow cytometric sorting was used to obtain a population of cells with uniformly high CD20 expression (38C13-huCD20). These cells maintained a high level of human CD20 expression during in vitro culturing and passage in immunocompetent $\mathrm{C} 3 \mathrm{H}$ mice. 38C13 and 38C13-huCD20 tumor cells were maintained in RPMI 1640 medium supplemented with $10 \%$ heat-inactivated fetal bovine serum, $2 \mathrm{mM}$ L-glutamine, penicillin at $100 \mathrm{U} / \mathrm{mL}$, streptomycin at $100 \mu \mathrm{g} / \mathrm{mL}$, and $50 \mu \mathrm{M}$ 2-mercaptoethanol. All media and supplements were obtained from Invitrogen. Six- to 8-wk-old female $\mathrm{C} 3 \mathrm{Hf} / \mathrm{Sed} / \mathrm{Kam}$ mice were bred and housed at the UCLA Defined Pathogen Colony according to a protocol approved by the UCLA Chancellor Animal Research Committee. Tumors were established by subcutaneous injection of $5 \times 10^{3}$ cells above each shoulder as described previously (14).

\section{Human CD20 Surface Expression by 38C13-huCD20 Cells}

CD20 levels on 38C13-huCD20 were quantitated, and 3 human B-cell lymphoma lines were used extensively for CD20 xenograft studies (Daudi, Raji, and Ramos) with flow cytometry. Cell lines were stained with PE-labeled anti-human CD20 antibody or к-PElabeled control mouse IgG1 antibody (BD Biosciences). Samples were run on a FACSCalibur flow cytometer (BD Biosciences), and data were analyzed with FCS Express V3 software (De Novo Software). For confirmation of human CD20 expression in vivo, mice were inoculated subcutaneously with $5 \times 10^{3} 38 \mathrm{C} 13$-huCD20 tumors on day 0 . Some mice were injected intravenously with $1 \mathrm{mg}$ of rituximab $4 \mathrm{~h}$ before tumor collection. On day 14 , tumors were removed, placed in formalin for $8 \mathrm{~h}$, transferred to $70 \%$ ethanol, and embedded in paraffin. The sections were deparaffinized with xylene and rehydrated through graded ethanol. Endogenous peroxidase activity was blocked with $3 \%$ hydrogen peroxide in methanol for 10 min. Heat-induced antigen retrieval (HIER) was performed for all sections with $0.01 \mathrm{M}$ sodium citrate buffer ( $\mathrm{pH}$ 6.0) in a vegetable steamer at $95^{\circ} \mathrm{C}$ for $25 \mathrm{~min}$. Mouse monoclonal antibody to human CD20 (Dako Corp.) and rabbit polyclonal antibody to human IgG1 for the detection of rituximab were applied at dilutions of 1:1,000 and 1:300, respectively, for $45 \mathrm{~min}$ at room temperature. The signal was detected with horseradish peroxidase EnVision kits (Dako Corp.) and visualized with the diaminobenzidine reaction. The sections were counterstained with hematoxylin.

\section{Small-Animal PET Imaging}

Before imaging studies were conducted, thyroid uptake was blocked with Lugol solution (Sigma-Aldrich) and stomach uptake was blocked by gastric lavage with potassium perchlorate as previously described (16). Mice were serially imaged under anesthesia at about 4 and $20 \mathrm{~h}$ after intravenous injection of radioactivity, using a Focus 220 microPET scanner (Siemens Preclinical Solutions). The acquisition time was $10 \mathrm{~min}$ (one bed position), and images were reconstructed with a filtered backprojection algorithm $(29,30)$. After the last scan, mice were euthanized, tumors and organs were excised and weighed, and activity was counted with a Wallac WIZARD automatic $\gamma$-counter (Perkin-Elmer Life and Analytic Sciences Inc.). The injected dose was corrected for labeling efficiency and immunoreactivity, and the percentage injected dose per gram of tissue (\%ID/g), along with the SD, was calculated and decay corrected. Images were displayed with AMIDE software (31), and regions of interest (ROIs) were drawn as described previously (16) and quantitated by use of a cylinder with a known weight and radioactivity to determine a calibration factor (MBq per voxel). ROIs were also drawn to calculate ratios for CD20-positive 
tumors, CD20-negative tumors, and soft tissues. All significance testing was done at the 0.05 level with a one-tailed Student $t$ test.

\section{RESULTS}

\section{In Vitro Characterization of Engineered}

Anti-CD20 Antibody Fragments

Expression and SDS-PAGE. Engineered anti-CD20 antibody fragments (minibody and scFv-Fc DM) (Fig. 1A) were expressed at $4-10 \mu \mathrm{g} / \mathrm{mL}$ in terminal cultures of the mouse myeloma cell line NSO, as determined with an enzymelinked immunosorbent assay. After affinity chromatography, purified proteins were analyzed by SDS-PAGE (Fig. 1B). Both the minibody and scFv-Fc DM migrated as covalent dimers, consistent with their predicted molecular masses of approximately 80 and $103 \mathrm{kDa}$, respectively, under nonreducing conditions and as monomers of approximately 40 and $51.5 \mathrm{kDa}$, respectively, under reducing conditions.

Size Exclusion Chromatography. Size exclusion chromatography verified that the anti-CD20 minibody and scFv-Fc DM were eluted at times corresponding to those of correctly folded dimers with the expected molecular masses (Fig. 1C). As expected, the minibody eluted slightly later than scFv-Fc DM-31.6 versus $29.9 \mathrm{~min}$-consistent with their size difference. The purity of the proteins was determined from the size exclusion chromatography to be greater than $90 \%$.

CD20-Binding Studies. Binding to the target antigen was demonstrated by indirect immunofluorescence cell surface staining of 38C13-huCD20 cells incubated with purified protein by flow cytometry (Fig. 1D). CD20 binding by the minibody and scFv-Fc DM shifted the cells to the right, indicating specific binding. The binding of rituximab to the cells is also shown.

\section{Expression of Target CD20 Antigen by 38C13-huCD20 Lymphoma Cells In Vivo and In Vitro}

To evaluate our anti-CD20 immunoPET imaging agents in vivo, we chose to use the 38C13-huCD20 B-cell lymphoma model. This fully syngeneic model allows for physiologic tumor growth in a natural immunocompetent host in which tumor cell adhesion, tumor metastasis, and adaptive immune effector mechanisms are fully functional. As shown in Figure 2A, cultured 38C13-huCD20 cells expressed high levels of human CD20, comparable to those found on human B-cell lymphoma lines commonly used as lymphoma xenografts (32). On subcutaneous injection of 38C13-huCD20 cells into $\mathrm{C} 3 \mathrm{H}$ mice, tumors grew rapidly, and immunohistochemical staining of excised tumors demonstrated high levels of human CD20 expression (Fig. 2B). Penetration of intact rituximab into growing tumors was demonstrated by intravenous injection, tumor excision $4 \mathrm{~h}$ later, and staining with antibody to human $\operatorname{IgG1}$; prominent staining was observed (data not shown). Together, these results indicated that human CD20 is expressed at levels similar to those seen with typical human B-cell lymphoma lines and that in vivo rituximab can recognize human CD20 expressed in this murine B-cell lymphoma model.

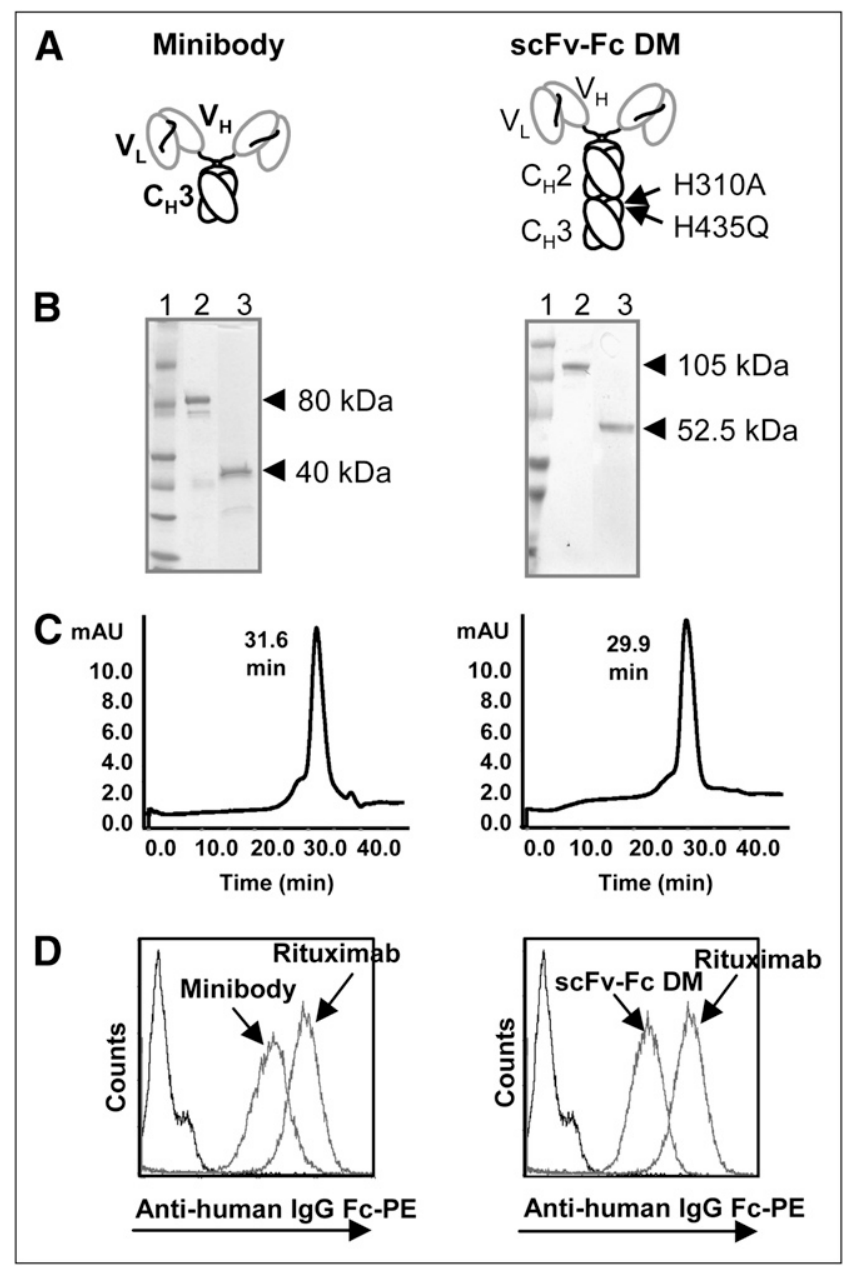

FIGURE 1. Characterization of purified rituximab minibody and scFv-Fc DM. (A) Schematic presentations of minibody and scFv-Fc DM. Both proteins assemble into covalent bound homodimers through cysteines in hinge region. Two mutations ( $\mathrm{H} 310 \mathrm{~A}$ and $\mathrm{H} 435 \mathrm{Q})$ present in Fc region are indicated. $\mathrm{C}_{\mathrm{H}}=$ constant heavy; $\mathrm{V}_{\mathrm{H}}=$ variable heavy; $\mathrm{V}_{\mathrm{L}}=$ variable light. (B) Coomassie blue staining after SDS-PAGE of purified proteins under nonreducing (lane 2) and reducing (lane 3) conditions. Lane 1 contains molecular marker. (C) Size exclusion chromatography analysis of purified minibody (left) and scFv-Fc DM (right). $\mathrm{mAU}=$ milli-absorbance unit. (D) Flow cytometric analysis of CD20 binding by rituximab antibody fragments. Purified proteins were assayed for binding to 38C13-huCD20 cells. Bound protein was detected with PE-conjugated goat antihuman (FC-specific) antibodies. Rituximab was used as positive control, and secondary antibody alone was used as negative control.

\section{In Vivo Characterization of ${ }^{124} \mid$-Labeled Engineered Anti-CD20 Antibody Fragments}

Small-Animal PET Imaging with ${ }^{124}$ I-Labeled Anti-CD20 $s c F v-F c$ DM. scFv-Fc DM was evaluated in $\mathrm{C} 3 \mathrm{H}$ mice bearing 38C13-huCD20 and 38C13 tumors averaging (mean \pm SD) $91 \pm 92 \mathrm{mg}$ (range, 28-225 mg) and $321 \pm 199 \mathrm{mg}$ (range, 93-565 mg) in weight, respectively. These mice were each injected with approximately $3.5 \mathrm{MBq}$ of ${ }^{124} \mathrm{I}-\mathrm{scFv}-\mathrm{Fc} \mathrm{DM}$ 


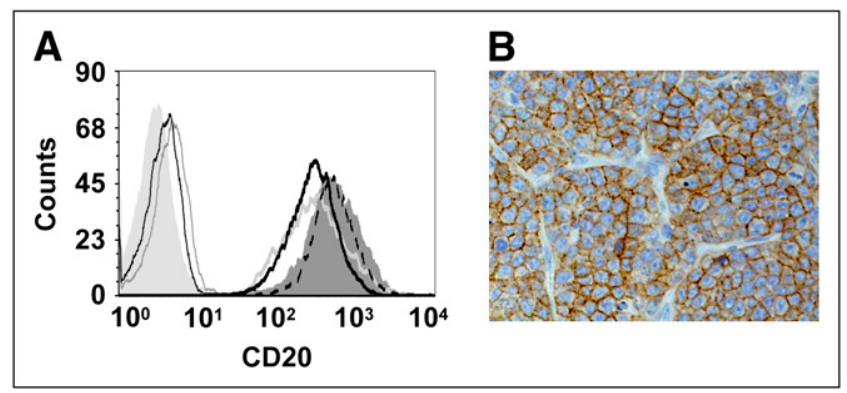

FIGURE 2. 38C13-huCD20 cells express surface human CD20 at levels comparable to human B-cell lymphoma xenograft lines. (A) Flow cytometric analysis of cells stained with PE-labeled anti-human CD20 antibody, showing surface staining of 38C13-huCD20 (dark gray histogram), Daudi (dotted black line), Raji (thick light gray line), Ramos (thick black line), and wild-type, non-CD20-expressing 38C13 (thin black line) cell lines. Controls included unstained 38C13huCD20 cells (light gray histogram) and PE-labeled isotype control antibody (thin light gray line). (B) Immunohistochemistry for human CD20 expression on 38C13-huCD20 cells in vivo. Day 14-established 38C13-huCD20 tumors grown in wild-type $\mathrm{C} 3 \mathrm{H}$ mice were excised, stained with anti-human CD20 antibody, and detected with peroxidase.

(specific activity, $0.066 \mathrm{MBq} / \mu \mathrm{g}$ ), and whole-body scans were obtained 4 and $21 \mathrm{~h}$ after administration. At $4 \mathrm{~h}$, radioactivity was seen in both tumors and normal organs (Fig. 3A). By $21 \mathrm{~h}$, the nonspecific activity in tumors and organs had cleared, and only CD20-positive tumors showed a strong signal. After the last scan, tumors and organs were harvested, and the \% ID/g was calculated and is shown in Figure 3A. The average uptake in CD20-positive tumors was $6.0 \pm 2.0 \% \mathrm{ID} / \mathrm{g}$, significantly higher than the uptake in control 38C13 (CD20-negative) tumors $(1.6 \pm 0.6 \% \mathrm{ID} / \mathrm{g})(P=0.007)$ and blood $(1.9 \pm 0.4$ $\% \mathrm{ID} / \mathrm{g})(P=0.011)$. Uptake in the liver, kidneys, spleen, and lungs was less than $2 \% \mathrm{ID} / \mathrm{g}$ and was significantly lower than that in tumors $(P<0.05)$. In these mice, the ratio of CD20positive tumors to CD20-negative tumors was $3.9 \pm 0.7$, and the ratio of CD20-positive tumors to blood ratio was $3.1 \pm 1.2$. The ratios of CD20-positive tumors to CD20-negative tumors at 4 and $21 \mathrm{~h}$, determined from ROIs, were $1.2 \pm 0.2$ and $2.4 \pm$ 0.8 , respectively, and the ratios of CD-positive tumors to soft tissue were $4.3 \pm 1.4$ and $9.9 \pm 4.6$, respectively (Table 1 ).

Small-Animal PET Imaging with ${ }^{124}$ I-Labeled Anti-CD2O Minibody. Tumor targeting of the anti-CD20 minibody was evaluated in mice bearing 38C13-huCD20 and 38C13 tumors averaging $59 \pm 32 \mathrm{mg}$ (range, $34-106 \mathrm{mg}$ ) and $71 \pm 54 \mathrm{mg}$ (range, 10-134 mg), respectively. The mice were each injected with approximately $3.9 \mathrm{MBq}$ of ${ }^{124}$ I-labeled minibody (specific activity, $0.069 \mathrm{MBq} / \mu \mathrm{g}$ ), and whole-body scans were obtained 4 and $21 \mathrm{~h}$ after administration. As with scFv-Fc DM, activity in both tumors and normal organs was seen at $4 \mathrm{~h}$, but at $21 \mathrm{~h}$, activity persisted only in CD20positive tumors (Fig. 3B). At $21 \mathrm{~h}$, mice were sacrificed, tumors were excised, and the $\% \mathrm{ID} / \mathrm{g}$ was calculated (Fig. 2B). The average uptake in CD20-positive tumors was
$12.9 \pm 3.4 \% \mathrm{ID} / \mathrm{g}$, and that in control $38 \mathrm{C} 13$ xenografts was significantly lower, at $1.9 \pm 0.5 \% \mathrm{ID} / \mathrm{g}(P=0.003)$. Also, the liver, kidneys, spleen, and lungs had activities (all $<2 \% \mathrm{ID} / \mathrm{g}$ ) that were significantly lower than the activity in CD20-positive tumors $(P<0.05)$. The activity in the blood $(2.8 \pm 0.5 \% \mathrm{ID} / \mathrm{g})$ was also significantly lower than the activity in CD20-positive tumors $(P=0.004)$. The ratio of $\mathrm{CD} 20$-positive tumors to CD20-negative tumors was $7.0 \pm$ 3.1, and the ratio of CD20-positive tumors to blood was $4.7 \pm$ 1.4. ROIs revealed ratios of CD20-positive tumors to CD20negative tumors of $2.2 \pm 0.8$ at $4 \mathrm{~h}$ and $4.0 \pm 0.7$ at $21 \mathrm{~h}$. The ratio of CD20-positive tumors to soft tissue at $4 \mathrm{~h}$ was $4.6 \pm$ 0.4 ; by $21 \mathrm{~h}$, this ratio had increased by more than 4-fold to $17.0 \pm 6.7$ (Table 1). Thus, both anti-CD20 antibody fragments offered cell surface target-specific imaging in vivo, with the minibody achieving higher-contrast images.

\section{In Vivo Characterization of ${ }^{64} \mathrm{Cu}-\mathrm{DOTA}-M i n i b o d y$ by Small-Animal PET Imaging}

The minibody was also evaluated in the same tumor model after being labeled with a residualizing radiometal to evaluate CD20-positive tumor targeting and normal organ uptake. The minibody was conjugated to DOTA, radiolabeled with ${ }^{64} \mathrm{Cu}$, and evaluated in mice bearing 38C13-huCD20 tumors $(n=2)$ and control $38 \mathrm{C} 13$ tumors $(n=3)$ with average weights of $26 \pm 20$ and $79 \pm 38 \mathrm{mg}$, respectively. The mice were each injected with approximately $3.7 \mathrm{MBq}$ of ${ }^{64} \mathrm{Cu}$-DOTA-minibody (specific activity, $0.042 \mathrm{MBq} / \mu \mathrm{g}$ ). Whole-body images were obtained at 4 and $19 \mathrm{~h}$; after the last scan, mice were euthanized, organs were harvested, and activity was counted to calculate the $\% \mathrm{ID} / \mathrm{g}$. The average uptake in 38C13-huCD20 tumors was $6.5 \pm 3.8 \% \mathrm{ID} / \mathrm{g}$, and the uptake in control $38 \mathrm{C} 13$ xenografts was $4.7 \pm 1.7 \% \mathrm{ID} / \mathrm{g}$; these values resulted in a ratio of 1.4 , which was 5 times lower than the ratio obtained with the ${ }^{124}$ I-labeled minibody.

The images obtained at 4 and $19 \mathrm{~h}$ showed activity in both types of tumors (Fig. 4). The activities in the tumors, liver, and kidneys, calculated from the biodistributions and ROIs, are shown in Figure 4. ROIs were drawn only on the largest, most clearly imaged CD20-positive tumors in the mouse shown in Figure 4. Levels of uptake in CD20-positive tumors at 4 and $19 \mathrm{~h}$, determined by ROI analyses, were 11.4 and $8.1 \% \mathrm{ID} / \mathrm{g}$, respectively; these values corresponded to the activity measured at the time of sacrifice $(9.1 \% \mathrm{ID} / \mathrm{g}$ at $19 \mathrm{~h})$. The ROIs of the CD20-negative tumors $(n=3)$ resulted in $\% \mathrm{ID} / \mathrm{g}$ values of $4.9 \pm 1.1$ and $4.2 \pm 1.1$ at 4 and $19 \mathrm{~h}$, respectively. The resulting ratios of CD20-positive tumors to CD20-negative tumors were 2.3 at $4 \mathrm{~h}$ and 1.9 at $19 \mathrm{~h}$. Thus, compared with the results obtained with the ${ }^{124}$ I-labeled minibody, CD20-positive tumor-specific imaging was less favorable with the ${ }^{64} \mathrm{Cu}$-DOTA-minibody because of a high background signal in control tumors and normal organs.

\section{DISCUSSION}

In this work, we sought to develop novel immunoPET imaging agents targeting the CD20 cell surface antigen 


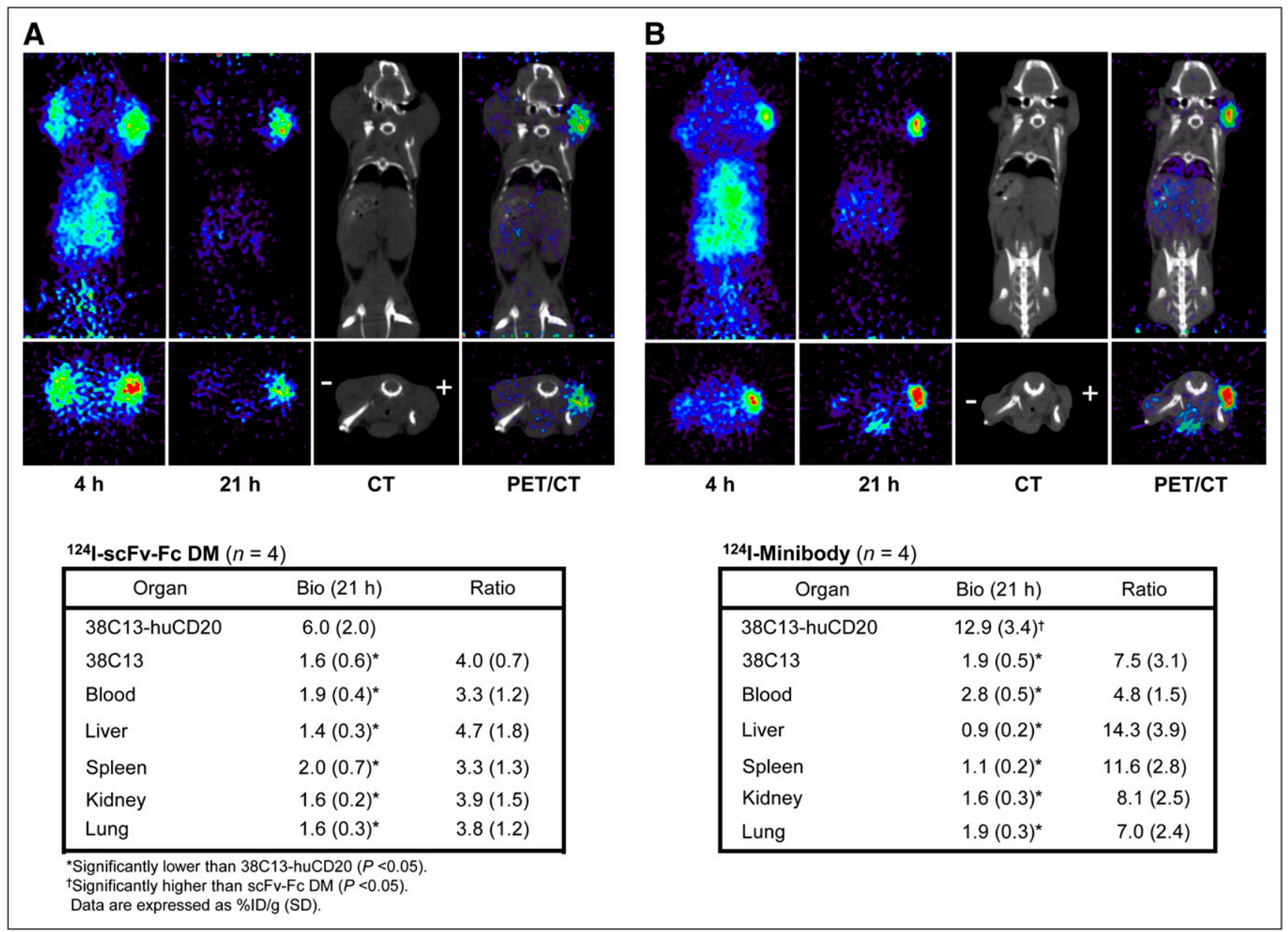

FIGURE 3. Serial small-animal PET images of mice bearing 38C13-huCD20 (+) and wild-type $38 \mathrm{C} 13(-)$ tumors at 4 and $21 \mathrm{~h}$ after administration of radioiodinated anti-CD20 scFv-Fc DM (A) and minibody (B). Both coronal slices (top row) and transverse slices (bottom row) are shown. PET/CT scan overlay images at $21 \mathrm{~h}$ are shown. Biodistribution (Bio) of radioiodinated proteins at time of sacrifice $(21 \mathrm{~h})$ and tumor-to-organ ratios are shown in tables accompanying images. Uptake in tissues was measured by ex vivo weighing and counting in $\gamma$-counter.

expressed by most human lymphomas. We described the generation of 2 antibody fragments of different sizes and compared their properties as imaging agents for CD20expressing tumors. Although both fragments had low immunoreactivities $(32 \%-38 \%)$ after radioiodination, they

\begin{tabular}{|c|c|c|c|c|}
\hline \multirow[b]{3}{*}{ Agent } & \multicolumn{4}{|c|}{ Mean ratio of: } \\
\hline & \multicolumn{2}{|c|}{$\begin{array}{c}38 \mathrm{C} 13-\mathrm{huCD} 20 \\
\text { to } 38 \mathrm{C} 13\end{array}$} & \multicolumn{2}{|c|}{$\begin{array}{l}\text { 38C13-huCD20 } \\
\text { to soft tissue }\end{array}$} \\
\hline & $4 \mathrm{~h}$ & $21 \mathrm{~h}$ & $4 \mathrm{~h}$ & $21 \mathrm{~h}$ \\
\hline scFv-Fc DM & $1.2(0.2)$ & $2.4(0.8)^{\star}$ & $4.3(1.4)$ & $9.9(4.6)^{*}$ \\
\hline Minibody & $2.2(0.8)$ & $4.0(0.7)^{\star}$ & $4.6(0.4)$ & $17.0(6.7)^{*}$ \\
\hline $\begin{array}{l}{ }^{*} \text { Significantl} \\
\text { Data in parentr }\end{array}$ & $\begin{array}{l}\text { higher tha } \\
\text { ses are } \pm\end{array}$ & $\begin{array}{l}\text { value at } 4 \\
\text { D. } n=4 \mathrm{fc}\end{array}$ & $\begin{array}{l}(P<0.0 \\
\text { both ager }\end{array}$ & \\
\hline
\end{tabular}

were both able to target the tumors well in vivo. Because the low immunoreactivities could have been attributable to modified tyrosines in the antigen-binding region, sitespecific radiolabeling may be a better labeling approach for these fragments. Still, in this study, the minibody exhibited better (2-fold) tumor targeting than scFv-Fc DM at $21 \mathrm{~h}$, producing excellent-quality, high-contrast images. This result was unexpected because iodinated anti-CEA scFvFc DM has been shown to have a slightly longer serum half-life $(8.0 \mathrm{~h})$ than the iodinated anti-CEA minibody (half-life, 5.3-7.0 h) $(13,14,33)$. This discrepancy may be attributable to the $\mathrm{Fc}$ region of the fragments in the 2 systems, namely, IgG1 and IgG4 for anti-CEA and antiCD20 fragments, respectively. We chose to use the IgG4 Fc region to minimize interactions with other immune cells because $\operatorname{IgG1}$, as opposed to $\mathrm{IgG} 4$, permits complement activation and strong effector-mediated cell killing by antibody-mediated cytotoxicity (34). In humans, the mean 


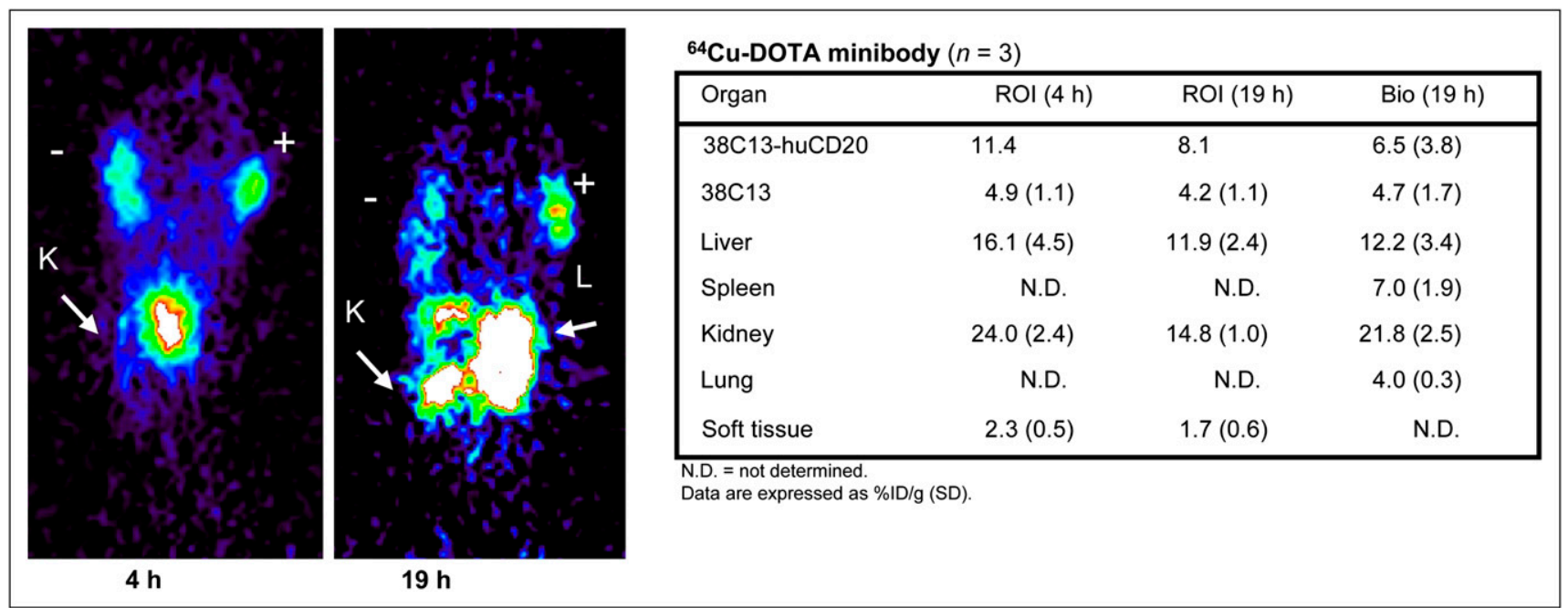

FIGURE 4. Coronal serial small-animal PET images of mouse bearing 38C13-huCD20 (+) and wild-type 38C13 (-) tumors at 4 and $19 \mathrm{~h}$ after administration of ${ }^{64} \mathrm{Cu}$-labeled, DOTA-conjugated anti-CD20 minibody. $\mathrm{K}=$ kidney; $\mathrm{L}=$ liver. Estimated activities from drawn ROls in $38 \mathrm{C} 13$, liver, spleen, kidney, lung, and soft tissue at 4 and $19 \mathrm{~h}$ are shown in table beside image along with activities present in tissues at time of sacrifice (19 h). Uptake in tissues was measured by ex vivo weighing and counting in $\gamma$-counter. ROls for 38C13-huCD20 were drawn from one tumor. Bio = biodistribution.

serum half-life of $\operatorname{IgG} 1$ is $36.3 \pm 9.2 \mathrm{~d}$, and that of $\operatorname{IgG} 4$ is $15.6 \pm 4.5 \mathrm{~d}(35)$. This difference in serum half-lives was also observed in mice, with residence times of $199.0 \pm 9.8$ $\mathrm{h}$ for IgG1 and $77.3 \pm 10.1 \mathrm{~h}$ for IgG4 (36). When the IgG4 $\mathrm{C}_{\mathrm{H}} 2-\mathrm{C}_{\mathrm{H}} 3$ domains were exchanged with the IgG1 $\mathrm{C}_{\mathrm{H}} 2-\mathrm{C}_{\mathrm{H}} 3$ domains, the serum half-life increased to $281.5 \pm 10.1 \mathrm{~h}$; interestingly, this value was higher than that for either parental IgG.

Mutations in the $\mathrm{C}_{\mathrm{H}} 2-\mathrm{C}_{\mathrm{H}} 3$ domains have identified residues important for high-affinity binding to FcRn (19). The histidine residue at position 435 in the $\mathrm{C}_{\mathrm{H}} 3$ domain was shown to have a dramatic effect on this interaction for human IgG1, whereas H433 had little effect. However, for human IgG4, H433 has been implicated to be more important than H435 (37). scFv-Fc DM, used in this work, contains 2 mutations in the $\mathrm{Fc}$ region, $\mathrm{H} 310 \mathrm{~A}$ in $\mathrm{C}_{\mathrm{H}} 2$ and $\mathrm{H} 435 \mathrm{~A}$ in $\mathrm{C}_{\mathrm{H}} 3$. The shorter serum half-life and the presence of these mutations in the IgG4 Fc region may explain the lower activity observed in the blood at $21 \mathrm{~h}$ relative to that observed with the minibody. Because the minibody contains no mutation in the $\mathrm{C}_{\mathrm{H}} 3$ domain, it is possible that the minibody has some interaction with FcRn that enables it to stay in the blood slightly longer than the larger fragment, scFv-Fc DM.

The fact that the minibody has a longer residence time in the blood also explains the much higher tumor uptake observed with this fragment at $21 \mathrm{~h}$. The radioactivity measured in tumors with the minibody was about 2-fold higher than that obtained with scFv-Fc DM. Such a difference has not been observed with the anti-CEA minibody and $\mathrm{scFv}-\mathrm{Fc} \mathrm{DM}$, with reported tumor uptake levels of 12.6, 15.7 , and $29.1 \% \mathrm{ID} / \mathrm{g}$ for the iodinated minibody $(12,13,33)$ and $18.6 \% \mathrm{ID} / \mathrm{g}$ for iodinated scFv-Fc (38) at $24 \mathrm{~h}$. The anti-
CD20 minibody exhibited other superior properties over scFv-Fc DM, such as high ratios of CD20-positive tumors to CD20-negative tumors and soft tissue.

The minibody was also labeled with ${ }^{64} \mathrm{Cu}$ and evaluated for imaging in tumor-bearing mice. However, even at $19 \mathrm{~h}$, this agent showed inferior ratios of CD20-positive tumor uptake to CD20-negative tumor uptake and persistent highlevel uptake in normal kidneys, liver, and bowel. Because the molecular mass of the minibody is above the threshold clearance of the kidneys, significant retention of activity in the liver relative to the tumor was not unexpected, as this had been observed previously in other tumor models $(15,17)$. However, this phenomenon could also be attributable to an alteration in the biodistribution properties of the minibody by the DOTA chelator. Such an alteration was observed for an antineuroblastoma $\mathrm{F}\left(\mathrm{ab}^{\prime}\right)_{2}$ fragment when it was chelated to 2 analogous copper chelators with different charges (39). Thus, for further development of CD20 immunoPET imaging, we favor the ${ }^{124}$ I-labeled minibody format.

The human CD20-specific PET agents described here offer new opportunities to image B-cell lymphomas in both preclinical animal models and humans. Our specific imaging of human CD20-positive lymphomas in mice demonstrated that ${ }^{124}$ I-labeled rituximab minibody fragments can serve as a tool for noninvasive in vivo monitoring of lymphoma growth and metastasis. This imaging technique should allow the assessment of disease spread in mice without the high levels of background signal in the brain, heart, bowel, kidneys, and bladder seen with ${ }^{18}$ F-FDG PET of lymphomas in mice (40). In the immunocompetent model that we described here, anti-CD20 immunoPET imaging could be used to study responses to therapies depending on an intact 
adaptive immune system, such as tumor antigen vaccines (41). We recently transduced another murine B-cell lymphoma (A20, BALB/c) with the human CD20 gene for propagation in BALB/c human CD20 transgenic mice (unpublished observations). In clinics, anti-CD20 immunoPET imaging might be used to increase the sensitivity of PET in cases of low tumor burden or in cases of indolent lymphomas, in which the sensitivity of ${ }^{18} \mathrm{~F}$-FDG PET can be as low as $50 \%(9,10)$.

CD20-specific imaging might also have use in imaging of the B-cell compartment in other experimental or pathologic states. With further refinements in sensitivity, antiCD20 immunoPET imaging might be used for the B-cell compartment in human CD20 transgenic mice, either during immune reconstitution after B lymphocyte-depleting therapies (42) or in autoimmune diseases in which collections of autoimmune B cells contribute to pathogenesis (43). Such imaging might increase understanding of B-cellmediated disease states.

In future studies, it will be important to determine whether pretreatment with rituximab interferes with subsequent anti-CD20 immunoPET imaging of lymphomas via blockade of rituximab-binding sites on CD20. Studies with human CD20 transgenic mice will help clarify this issue. As rituximab levels fall after the cessation of therapy, it is likely that anti-CD20 immunoPET reagents will be able to bind to an increasing number of available sites on the tumor cell surface. Indeed, CD20 immunoPET may be useful for determining whether tumor CD20 sites are saturated after a given dose of rituximab or at specific intervals after rituximab administration.

\section{CONCLUSION}

This work demonstrates rapid targeting of CD20-positive lymphomas in vivo by 2 engineered antibody fragments, a minibody and scFv-Fc DM. Both fragments produced highcontrast, target-specific PET images in tumor-bearing mice at $21 \mathrm{~h}$. The better candidate was the minibody, which exhibited superior tumor uptake and, combined with rapid clearance, yielded higher ratios of CD20-positive tumors to CD20-negative tumors and tissues. When the minibody was radiolabeled with ${ }^{64} \mathrm{Cu}$, lower ratios were obtained because of residual activity in CD20-negative tumors and the liver. Thus, ${ }^{124} \mathrm{I}$ is the preferred radiolabel because of lower background activity in normal tissues, enhancing the overall image.

\section{ACKNOWLEDGMENTS}

This work was supported by NIH grants P50 CA107399, P50 CA086306, and CA119367 and by the Margaret Early Medical Research Trust. The production of ${ }^{64} \mathrm{Cu}$ at Washington University School of Medicine was supported by NCI grant R24 CA86307. Support was also provided by grants CA33572 (City of Hope Comprehensive Cancer Center), CA16042 (Jonsson Comprehensive Cancer Center), and CI-26-05 (Damon Runyon Cancer Research Foundation). We thank Karl B. Bauer for excellent technical support. We are especially grateful to Dr. David Stout, Waldemar Ladno, and Judy Edwards at the Crump Institute for Molecular Imaging at UCLA for their assistance with the small-animal PET/CT scans. Thanks are also extended to the Jonsson Comprehensive Cancer Center at UCLA and the Center for AIDS Research Flow Cytometry Core Facility at UCLA.

\section{REFERENCES}

1. Tedder TF, Engel P. CD20: a regulator of cell-cycle progression of B lymphocytes. Immunol Today. 1994;15:450-454.

2. Cragg MS, Walshe CA, Ivanov AO, Glennie MJ. The biology of CD20 and its potential as a target for mAb therapy. Curr Dir Autoimmun. 2005;8:140-174.

3. McLaughlin P, Grillo-Lopez AJ, Link BK, et al. Rituximab chimeric anti-CD20 monoclonal antibody therapy for relapsed indolent lymphoma: half of patients respond to a four-dose treatment program. J Clin Oncol. 1998;16:2825-2833.

4. Coiffier B, Lepage E, Briere J, et al. CHOP chemotherapy plus rituximab compared with $\mathrm{CHOP}$ alone in elderly patients with diffuse large-B-cell lymphoma. $N$ Engl J Med. 2002;346:235-242.

5. Marcus R, Imrie K, Solal-Celigny P, et al. Phase III study of R-CVP compared with cyclophosphamide, vincristine, and prednisone alone in patients with previously untreated advanced follicular lymphoma. J Clin Oncol. 2008;26:4579-4586.

6. Cartron G, Watier H, Golay J, Solal-Celigny P. From the bench to the bedside: ways to improve rituximab efficacy. Blood. 2004;104:2635-2642.

7. Witzig TE, White CA, Wiseman GA, et al. Phase I/II trial of IDEC-Y2B8 radioimmunotherapy for treatment of relapsed or refractory $\mathrm{CD} 20^{+} \mathrm{B}$-cell nonHodgkin's lymphoma. J Clin Oncol. 1999;17:3793-3803.

8. Vose JM, Wahl RL, Saleh M, et al. Multicenter phase II study of iodine-131 tositumomab for chemotherapy-relapsed/refractory low-grade and transformed low-grade B-cell non-Hodgkin's lymphomas. J Clin Oncol. 2000;18:13161323

9. Karam M, Novak L, Cyriac J, Ali A, Nazeer T, Nugent F. Role of fluorine-18 fluoro-deoxyglucose positron emission tomography scan in the evaluation and follow-up of patients with low-grade lymphomas. Cancer. 2006;107:175-183.

10. Tsukamoto $\mathrm{N}$, Kojima $\mathrm{M}$, Hasegawa $\mathrm{M}$, et al. The usefulness of ${ }^{18} \mathrm{~F}-$ fluorodeoxyglucose positron emission tomography $\left({ }^{18} \mathrm{~F}-\mathrm{FDG}-\mathrm{PET}\right)$ and a comparison of ${ }^{18} \mathrm{~F}$-FDG-PET with ${ }^{67}$ gallium scintigraphy in the evaluation of lymphoma: relation to histologic subtypes based on the World Health Organization classification. Cancer. 2007;110:652-659.

11. Wu AM, Olafsen T. Antibodies for molecular imaging of cancer. Cancer J. 2008;14:191-197.

12. Wu AM, Williams LE, Zieran L, et al. Anti-carcinoembryonic antigen (CEA) diabody for rapid tumor targeting and imaging. Tumor Targeting. 1999;4:47-58.

13. Hu S, Shively L, Raubitschek A, et al. Minibody: a novel engineered anticarcinoembryonic antigen antibody fragment (single-chain $\mathrm{Fv}-\mathrm{CH} 3$ ) which exhibits rapid, high-level targeting of xenografts. Cancer Res. 1996;56:30553061 .

14. Kenanova V, Olafsen T, Crow DM, et al. Tailoring the pharmacokinetics and positron emission tomography imaging properties of anti-carcinoembryonic antigen single-chain Fv-Fc antibody fragments. Cancer Res. 2005;65:622-631.

15. Olafsen T, Kenanova VE, Sundaresan G, et al. Optimizing radiolabeled engineered anti-p185HER2 antibody fragments for in vivo imaging. Cancer Res. 2005;65:5907-5916.

16. Sundaresan G, Yazaki PJ, Shively JE, et al. ${ }^{124} \mathrm{I}$-labeled engineered anti-CEA minibodies and diabodies allow high-contrast, antigen-specific small-animal PET imaging of xenografts in athymic mice. J Nucl Med. 2003;44:1962-1969.

17. Wu AM, Yazaki PJ, Tsai S, et al. High-resolution microPET imaging of carcinoembryonic antigen-positive xenografts by using a copper-64-labeled engineered antibody fragment. Proc Natl Acad Sci USA. 2000;97:8495-8500.

18. Leyton JV, Olafsen T, Lepin EJ, et al. Humanized radioiodinated minibody for imaging of prostate stem cell antigen-expressing tumors. Clin Cancer Res. 2008;14:74887496.

19. Medesan C, Matesoi D, Radu C, Ghetie V, Ward ES. Delineation of the amino acid residues involved in transcytosis and catabolism of mouse IgG1. J Immunol. 1997; 158:2211-2217.

20. Anderson DR, Hanna N, Leonard JE, Newman RA, Reff ME, Rastetter WH, inventors; IDEC Pharmaceuticals Corp., assignee. Therapeutic application of chimeric and radiolabeled antibodies to human B lymphocyte restricted 
differentiation antigen for treatment of B cell lymphoma. U.S. patent 5,736,137. April 7, 1998.

21. Yazaki PJ, Sherman MA, Shively JE, et al. Humanization of the anti-CEA T84.66 antibody based on crystal structure data. Protein Eng Des Sel. 2004; 17:481-489.

22. Whitlow M, Bell BA, Feng SL, et al. An improved linker for single-chain Fv with reduced aggregation and enhanced proteolytic stability. Protein Eng. 1993;6:989-995.

23. Olafsen T, Kenanova VE, Wu AM. Tunable pharmacokinetics: modifying the in vivo half-life of antibodies by directed mutagenesis of the Fc fragment. Nat Protocols. 2006;1:2049-2060.

24. Angal S, King DJ, Bodmer MW, et al. A single amino acid substitution abolishes the heterogeneity of chimeric mouse/human (IgG4) antibody. Mol Immunol. 1993;30:105-108.

25. Lewis MR, Kao JY, Anderson AL, Shively JE, Raubitschek A. An improved method for conjugating monoclonal antibodies with N-hydroxysulfosuccinimidyl DOTA. Bioconjug Chem. 2001;12:320-324.

26. Robertson EF, Dannelly HK, Malloy PJ, Reeves HC. Rapid isoelectric focusing in a vertical polyacrylamide minigel system. Anal Biochem. 1987;167:290294.

27. Bergman Y, Haimovich J. Characterization of a carcinogen-induced murine B lymphocyte cell line of C3H/eB origin. Eur J Immunol. 1977;7:413-417.

28. Golay J, Cittera E, Di Gaetano N, et al. The role of complement in the therapeutic activity of rituximab in a murine B lymphoma model homing in lymph nodes. Haematologica. 2006;91:176-183.

29. Kinahan PE, Rogers JG. Analytic 3D image reconstruction using all detected events. IEEE Trans Nucl Sci. 1989;36:964-968.

30. Defrise M, Kinahan PE, Townsend DW, Michel C, Sibomana M, Newport DF. Exact and approximate rebinning algorithms for 3-D PET data. IEEE Trans Med Imaging. 1997;16:145-158.

31. Loening AM, Gambhir SS. AMIDE: a free software tool for multimodality medical image analysis. Mol Imaging. 2003;2:131-137.

32. Clynes RA, Towers TL, Presta LG, Ravetch JV. Inhibitory Fc receptors modulate in vivo cytoxicity against tumor targets. Nat Med. 2000;6:443-446.
33. Yazaki PJ, Wu AM, Tsai SW, et al. Tumor targeting of radiometal labeled antiCEA recombinant $\mathrm{T} 84.66$ diabody and 84.66 minibody: comparison to radioiodinated fragments. Bioconjug Chem. 2001;12:220-228.

34. Jefferis R. Antibody therapeutics: isotype and glycoform selection. Expert Opin Biol Ther. 2007;7:1401-1413.

35. Alyanakian MA, Bernatowska E, Scherrmann JM, Aucouturier P, Poplavsky JL. Pharmacokinetics of total immunoglobulin $G$ and immunoglobulin $G$ subclasses in patients undergoing replacement therapy for primary immunodeficiency syndromes. Vox Sang. 2003;84:188-192.

36. Zuckier LS, Chang CJ, Scharff MD, Morrison SL. Chimeric human-mouse IgG antibodies with shuffled constant region exons demonstrate that multiple domains contribute to in vivo half-life. Cancer Res. 1998;58:3905-3908.

37. Raghavan M, Bonagura VR, Morrison SL, Bjorkman PJ. Analysis of the $\mathrm{pH}$ dependence of the neonatal $\mathrm{Fc}$ receptor/immunoglobulin $\mathrm{G}$ interaction using antibody and receptor variants. Biochemistry. 1995;34:14649-14657.

38. Kenanova V, Olafsen T, Williams LE, et al. Radioiodinated versus radiometal-labeled anti-carcinoembryonic antigen single-chain $\mathrm{Fv}-\mathrm{Fc}$ antibody fragments: optimal pharmacokinetics for therapy. Cancer Res. 2007; 67:718-726.

39. Zimmermann K, Gianollini S, Schubiger PA, Novak-Hofer I. A triglycine linker improves tumor uptake and biodistributions of 67-Cu-labeled anti-neuroblastoma MAb chCE7 F( $\left.\mathrm{ab}^{\prime}\right) 2$ fragments. Nucl Med Biol. 1999;26:943-950.

40. Brentjens RJ, Latouche JB, Santos E, et al. Eradication of systemic B-cell tumors by genetically targeted human $\mathrm{T}$ lymphocytes co-stimulated by CD80 and interleukin-15. Nat Med. 2003;9:279-286.

41. Betting DJ, Kafi K, Abdollahi-Fard A, Hurvitz SA, Timmerman JM. Sulfhydrylbased tumor antigen-carrier protein conjugates stimulate superior antitumor immunity against B cell lymphomas. J Immunol. 2008;181:4131-4140.

42. Gong $\mathrm{Q}, \mathrm{Ou} \mathrm{Q}, \mathrm{Ye} \mathrm{S}$, et al. Importance of cellular micro environment and circulatory dynamics in B cell immunotherapy. J Immunol. 2005;174:817826.

43. Ahuja A, Shupe J, Dunn R, Kashgarian M, Kehry MR, Shlomchik MJ. Depletion of B cells in murine lupus: efficacy and resistance. J Immunol. 2007;179:33513361 . 